\title{
Diferença da média de idade ao morrer, entre moradores das diferentes classes sociais do município de Santos, 2009-2010
}

\author{
Evelyn Lepka de $\operatorname{LIMA}^{(1)}$ \\ Marcos Montani CASEIRO(1) \\ Marcela Maria Carvalho PONTES(1)
}

${ }^{(1)}$ Centro Universitário Lusíada, Santos, SP, Brasil.

Recebido: 28 jan 2019 Aceito: 10 fev 2019

Autor de correspondência: evelynlepka@gmail.com

Conflito de interesses: Os autores declaram não haver nenhum interesse profissional ou pessoal que possa gerar conflito de interesses em relação a este manuscrito.

\section{Resumo}

Ao longo do século $X X$, o Brasil sofreu intensas modificações dos níveis de mortalidade e natalidade, resultantes da velocidade em que sucederam as transições demográfica e epidemiológica no país. Diferentemente do processo vivenciado pela Europa Ocidental e América do Norte, no Brasil, o descenso dos níveis de mortalidade e fecundidade ocorreu tardiamente, porém de maneira mais veloz. Ademais, a transição epidemiológica se deu na medida em que ocorreram transformações na estrutura de causas de morte. Por meio do desenvolvimento socioeconômico, avanços na escolaridade e renda, assim como na importação de conhecimento, tecnologia e ampliação do sistema público de saúde e de saneamento básico, houve uma substituição na ordem de importância das doenças. De infecto-parasitárias que atingia, sobretudo, jovens, pelas crônicas não-transmissíveis, incidentes nas idades mais velhas. No entanto, a melhor situação de saúde delineada pelos indicadores de mortalidade não se refletiu uniformemente em todas as regiões do país. Desigualdades socioeconômicas que assolam a sociedade brasileira são também responsáveis pelo fato de que regiões, estados e classes sociais se encontrem em momentos e fases distintas da transição demográfica e epidemiológica convivendo-se, ainda hoje, com mazelas -incluindo as doenças- geradas pelos estágios tanto atrasados, quanto avançados das transições. Esses altos níveis de interação entre doenças decorrentes de exposição aos riscos tradicionais (ausência de saneamento básico, poluição intradomiciliar e desnutrição) e aos riscos modernos (poluição industrial e violência) terá, como segmento mais vulnerável, as populações mais empobrecidas. Esses riscos, por sua vez, se originam das condições heterogêneas de existência e de acesso a bens e serviços, inclusive os de saúde. Por consequência, o excedente de doenças provocado pelas desigualdades em saúde poderia acarretar nos grupos mais vulneráveis mortalidade precoce, sobrecarga de determinados procedimentos médicos, maiores demandas de serviços sociais e redução da possibilidade de ascensão social. Ou seja, numa determinada sociedade territorializada, a expressão de diferenciais no risco de adoecer ou morrer. Estudos epidemiológicos realizados pelo mundo constam diferentes perfis de causas de óbito e riscos de mortalidade segundo características socioeconômicas de grupos populacionais, mostrando que a diminuição da 
mortalidade não atinge a população de modo generalizado. Muitos deles têm procurado contribuir no debate quanto ao desvelamento das associações existentes entre desigualdades socioeconômicas e desigualdades em saúde. $\mathrm{O}$ Black Report, estudo epidemiológico realizado na Inglaterra em 1982, aponta que os riscos de morte de trabalhadores manuais são maiores que os dos trabalhadores não manuais, apesar da universalidade da atenção à saúde na GrãBretanha. Além do mais, evidencia haver uma tendência de distanciamento nos riscos de morte entre classes sociais. O interesse pela produção de estudos sobre a desigualdade em mortalidade e saúde descreve uma longa trajetória histórica. No entanto, foi a partir do século XVIII, devido à efervescência política e social trazida pela revolução industrial, que ela se intensificou. Representante dessa vertente, apontado inclusive como fundador da epidemiologia social, Engels registrou as precárias condições de vida nos bairros operários de Manchester em "A situação da classe trabalhadora na Inglaterra". Nessa obra, Engels enfatizou os diferenciais do risco de morte prematura associados com a condição social, como, por exemplo, a duração média da vida em Liverpool, onde a expectativa de vida entre as classes mais elevadas situava-se em 35 anos, reduzindo-se para 22 anos entre negociantes e chegando a apenas 15 anos para os operários. $\mathrm{Na}$ década de 1970, com destaque para México, Equador e Brasil, ocorreu o surgimento de uma vertente teórica que buscou recuperar as ideias de causalidade social do processo saúde-doença, retomando, inclusive, a denominação de medicina social. Os integrantes desse movimento também assumiram uma vinculação com o pensamento revolucionário de sua época, que pode ser constatada pela nítida adesão ao ideário marxista. Essa escola latinoamericana promoveu uma reinterpretação da epidemiologia sob o marco teórico do materialismo histórico, reestabelecendo o processo saúde-doença como fenômeno socialmente determinado. Ainda dentro da perspectiva de estratos/classes sociais, encontram-se muitos estudos que abordam a dimensão espacial, atentando-se, principalmente, às desigualdades sócio-espaciais na mortalidade vivenciadas dentro dos municípios. Nesse campo emerge o conceito de espaço social, que ultrapassa a noção de espaço físico, uma vez que resgata a construção histórica e dimensão social do espaço. Ou seja, passa a representar as condições de vida das pessoas. Nele, estão embutidas as dimensões políticas, ideológicas e as necessidades econômicas que são determinantes para sua forma e estrutura de organização. Decerto, a operacionalização do conceito de condições de vida, através de variáveis e indicadores circunscritos no território, constitui uma estratégia para o entendimento da ocorrência e da distribuição de agravos à saúde. Além do mais, a estratégia pode se tornar uma contribuição para as adequações das ações de saúde às necessidades diferenciadas da população, uma vez que os próprios serviços de saúde são também organizados em base espacial. Diante dessa consideração, o objetivo deste estudo foi avaliar a distribuição socioespacial da média de idade ao morrer entre os bairros do município de Santos. Através do Censo IBGE 2010, realizou-se a busca dos óbitos registrados entre agosto de 2009 e julho de 2010. Esses dados foram 
estratificados por grupo de idade e bairro da pessoa falecida. Obteve-se a média ponderal de idade de óbito, seguido de geoprocessamento destas informações através do Software MAPINFO ${ }^{\circledR}$ 16, resultando no mapa da média de idade ao morrer por bairro da cidade de Santos. Como resultado, observou-se distribuição desigual da média de idade ao morrer entre os diferentes bairros de Santos, que por sua vez, representam as distintas classes sociais do município. Há destaque para a distribuição socioespacial dessa variável: os bairros da faixa litorânea possuem valores de média de idade ao morrer superiores aos da região central e noroeste da cidade, com destaque para a diferença entre os detentores da maior e menor média, que chega a 25 anos. Os dados demonstram os enormes desafios que ainda existem na busca pelo fim da desigualdade social, representada aqui, pela diferença de expectativa de vida conforme o pertencimento à determinada classe e, consequentemente, ao local de moradia. As classes subalternas morrem mais cedo do que as classes abastadas.

Descritores: Mortalidade; Classe social; Saúde Pública. 